\title{
Improvement in obstructive sleep apnea diagnosis and management wait times: A retrospective analysis of a home management pathway for obstructive sleep apnea
}

\author{
Samuel Alan Stewart PhD, Robert Skomro MD FRCPC, John Reid MD FRCPC, Erika Penz MD FRCPC, \\ Mark Fenton MD FRCPC, John Gjevre MD FRCPC, David Cotton MD FRCPC
}

\begin{abstract}
SA Stewart, R Skomro, J Reid, et al. Improvement in obstructive sleep apnea diagnosis and management wait times: A retrospective analysis of a home management pathway for obstructive sleep apnea. Can Respir J 2015;22(3):167-170.

Obstructive sleep apnea is a common condition within the Canadian population. The current gold standard for diagnosis and management of patients is in-laboratory (in-lab) polysomnography; however, the limited availability of testing options for patients has led to long wait times and increased disease burden within the population. The Sleep Research Laboratory in Saskatoon (Saskatchewan) implemented a home management program to run in parallel with the in-lab system several years ago in an effort to increase their capacity and reduce wait times. The present study was a retrospective analysis of all patients referred to the program between 2009 and 2012. The home management system has improved wait times by diagnosing and managing up to one-half of the referred patient population, reducing the wait for in-lab treatment from a median of 152 days in 2009 to 92 days in 2012 ( $\mathrm{P}<0.0001$ ). Moving forward, home management can provide a viable alternative to in-lab testing for patients who meet strict entry criteria, reducing the in-lab workload and, ultimately, reducing wait times.
\end{abstract}

Key Words: Monitoring, physiological; Polysomnography; Saskatchewan; Sleep apnea; Time factors; Time to treatment

$\mathrm{O}$ sstructive sleep apnea (OSA) is a common chronic respiratory condition. Recent reports estimate the prevalence of diagnosed OSA to be $3 \%$ of the adult Canadian population, with an additional $19 \%$ at high risk for the condition (1). It is believed that the majority of Canadian adults with OSA remain undiagnosed. OSA rates are on the rise, likely secondary to increasing obesity rates (2). OSA is typically diagnosed during in-laboratory (in-lab) polysomnography (PSG); however, current access to such testing in Canada is believed to be insufficient, although there is limited literature to verify this claim. Previous studies have relied on questionnaires to estimate wait times (3); however, no study has evaluated 'true' wait times for PSG using real-world patient data.

There has been increasing interest in home diagnosis and management pathways using a variety of cardiorespiratory home monitors and the use of automatic continuous positive pressure airway (auto-CPAP) technology. We previously published a randomized controlled trial validating the use of an OSA home-management pathway (4). Based on the results of this and other similar trials (5-9), we have implemented a centralized pathway for managing OSA patients with either in-lab PSG (referred to as 'sleep lab' [SL]) or at home using level III testing and auto-CPAP (referred to as home monitoring [HM]). There are currently no Canadian data regarding the impact of an HM pathway on wait times for in-lab PSG, on assignment rates between in-lab PSG and HM pathway or on the compliance with Canadian Thoracic Society OSA wait time guidelines.

The purpose of the present study was to provide retrospective analysis of referral patterns for the HM program from 2009 to 2012; to investigate the evolution of the patient assignment rates between the two diagnostic pathways over time; to investigate wait times in both
Améliorer les temps d'attente pour diagnostiquer et prendre en charge l'apnée obstructive du sommeil : l'analyse rétrospective d'une voie de prise en charge à domicile

\begin{abstract}
L'apnée obstructive du sommeil est un problème courant au sein de la population canadienne. La polysomnographie en laboratoire est la norme de référence pour la diagnostiquer et la prendre en charge, mais le nombre limité de tests disponibles a prolongé les temps d'attente et accru le fardeau de la maladie au sein de la population. Il y a quelques années, le Sleep Research Laboratory de Saskatoon, en Saskatchewan, a mis en œuvre un programme de prise en charge à domicile exploité parallèlement au système en laboratoire afin d'en accroître la capacité et de réduire les temps d'attente. La présente étude était une analyse rétrospective de tous les patients aiguillés vers le programme entre 2009 et 2012. Le système de prise en charge à domicile a réduit les temps d'attente, car il permet de diagnostiquer et de prendre en charge jusqu'à la moitié de la population de patients aiguillés. Ainsi, l'attente en vue du traitement en laboratoire est passée d'une médiane de 152 jours en 2009 à 92 jours en $2012(\mathrm{P}<0,0001)$. À l'avenir, la prise en charge à domicile pourra constituer une solution viable aux tests en laboratoire chez les patients qui respectent des critères d'admissibilité rigoureux, ce qui réduira la charge de travail en laboratoire et, au bout du compte, les temps d'attente.
\end{abstract}

pathways; and to determine compliance with current national guidelines on wait times for OSA diagnosis and management, and to determine the impact of HM implementation on wait times overall.

\section{METHODS}

The Sleep Disorders Centre at Saskatoon City Hospital and the University of Saskatchewan (Saskatoon, Saskatchewan) developed a streamlined process for triaging patients to either SL or HM in 2006/2007. Using standardized criteria, patients are assigned to either SL or HM after a visit with a respirologist/sleep medicine physician. The criteria for referral to HM are:

1. Absence of coexisting cardiac or respiratory disease.

2. Moderate to high pretest probability of OSA.

3. Low risk of hypoventilation.

4. Absence of coexisting sleep conditions such as insomnia or restless legs syndrome.

5. Ability to use level III technology at home with minimal supervision.

\section{SL pathway}

In-lab PSG was performed according to standard criteria (10) using the Sandman version 9 in-lab PSG system (Mallinckrodt Inc, Canada). Split-night PSG with CPAP titration was typically performed in cases of moderate to severe OSA according to current American Academy of Sleep Medicine criteria. OSA was defined as a decrease of flow by $\geq 90 \%$ for $\geq 10$ s accompanied by respiratory effort. Hypopnea was defined as $\geq 30 \%$ decrease in flow $\geq 10$ s duration accompanied by a $\geq 3 \%$ desaturation or arousal (5). OSA was defined as an apnea-hypopnea index (AHI) $\geq 5 / h$. 
TABLE 1

Sleep lab* (SL) and home monitoring (HM) summaries and patient demographics, according to year

\begin{tabular}{lcccc}
\hline & \multicolumn{4}{c}{ Year } \\
\cline { 2 - 5 } & $\mathbf{2 0 0 9}$ & $\mathbf{2 0 1 0}$ & $\mathbf{2 0 1 1}$ & $\mathbf{2 0 1 2}$ \\
\hline Patient referrals, $\mathbf{n}$ & & & & \\
$\mathrm{SL}$ & 1257 & 1333 & 973 & 764 \\
$\mathrm{HM}$ & 522 & 400 & 517 & 510 \\
Total & 1779 & 1733 & 1490 & 1274 \\
Patient procedures, $\mathbf{n}$ & & & \\
SL & 922 & 1184 & 1270 & 1251 \\
HM & 364 & 522 & 510 & 561 \\
Total & 1286 & 1706 & 1780 & 1812
\end{tabular}

Demographics according to referral year

Age, years,

$52.25 \pm 13.85 \quad 52.39 \pm 14.07 \quad 53.29 \pm 14.51 \quad 53.53 \pm 14.65$

$\mathrm{BMI}, \mathrm{kg} / \mathrm{m}^{2}$, mean \pm SD

$33.53 \pm 7.61 \quad 33.58 \pm 7.93$

$34.51 \pm 8.16$

$34.48 \pm 8.63$

Male sex

$1184(0.666) \quad 1100(0.636) \quad 977(0.659)$

(prop)

Female sex

$593(0.334) \quad 629(0.364) \quad 505(0.341)$

(prop)

\begin{tabular}{|c|c|c|c|c|}
\hline \multicolumn{5}{|c|}{ Disease severity according to procedure year } \\
\hline $\mathrm{HM}: \mathrm{AHI} 0$ to 5 & $41(11.3)$ & $55(10.5)$ & $42(8.2)$ & $65(11.6)$ \\
\hline $\mathrm{HM}: \mathrm{AHI}>5$ to 15 & $104(28.6)$ & $130(24.9)$ & $132(25.9)$ & $155(27.6)$ \\
\hline $\mathrm{HM}: \mathrm{AHI}>15$ to 30 & $92(25.3)$ & $141(27)$ & $126(24.7)$ & $156(27.8)$ \\
\hline $\begin{array}{l}\mathrm{HM}: \mathrm{AHI}>30 \text { to } \\
200\end{array}$ & $122(33.5)$ & $187(35.8)$ & $172(33.7)$ & $178(31.7)$ \\
\hline $\begin{array}{l}\text { HM: AHI data } \\
\text { missing }\end{array}$ & $5(1.4)$ & $9(1.7)$ & $38(7.5)$ & $7(1.2)$ \\
\hline HM: AHI, mean & 25.5 & 29.74 & 31.72 & 25.96 \\
\hline SL: $A H I 0$ to 5 & $132(14.3)$ & $253(21.4)$ & $318(25)$ & $336(26.9)$ \\
\hline SL: $\mathrm{AHI}>5$ to 15 & $151(16.4)$ & $260(22)$ & $327(25.7)$ & $328(26.2)$ \\
\hline SL: $\mathrm{AHI}>15$ to 30 & $112(12.1)$ & $154(13)$ & $215(16.9)$ & $202(16.1)$ \\
\hline $\begin{array}{l}\text { SL: } A H I>30 \text { to } \\
200\end{array}$ & $213(23.1)$ & $257(21.7)$ & $353(27.8)$ & $335(26.8)$ \\
\hline $\begin{array}{l}\text { SL: AHI data } \\
\text { missing }\end{array}$ & $314(34.1)$ & $260(22)$ & $57(4.5)$ & $50(4)$ \\
\hline SL: AHI, mean & 30.23 & 24.49 & 34.38 & 24.25 \\
\hline \multicolumn{5}{|c|}{ OSA diagnosis rate according to procedure year } \\
\hline SL & 0.851 & 0.772 & 0.831 & 0.823 \\
\hline $\mathrm{HM}$ & 0.774 & 0.79 & 0.766 & 0.768 \\
\hline
\end{tabular}

Data presented as $n$ (\%) unless otherwise indicated. *In-laboratory polysomnography. AHI Apnea-hypopnea index (events/h); BMI Body mass index; OSA Obstructive sleep apnea; prop Proportion

\section{HM pathway}

Cardiorespiratory home study was performed using an Embletta X10 (Embletta, USA) with the following channels: thermistor, pressure transducer, chest and abdominal effort channels, body position, heart rate and oxygen saturation. A trained PSG technologist instructed the patient on the use of the device during a $30 \mathrm{~min}$ teaching session. The patient was then provided with a device for use that night at home to be returned the following morning. The study was scored by a PSG technologist: hypopnea was defined as a decrease in flow $\geq 30 \%$, lasting $\geq 10$ s with $\geq 3 \%$ desaturation; OSA was defined as a decrease of flow by $\geq 90 \%$ for $\geq 10$ s accompanied by respiratory effort (5). All level III studies were subsequently reviewed by a sleep medicine physician and a decision was made as to whether to proceed with an auto-CPAP titration or to suggest in-lab PSG to the referring physician. Level III studies were deemed acceptable if there was $\geq 4 \mathrm{~h}$ of data in all channels. OSA was defined as AHI $\geq 5 / h$.

For patients who proceeded with auto-CPAP titration, a ResMed S8 or S9 (ResMed, USA) was used for a period of seven days. Studies were of acceptable quality if the following criteria were met: autoCPAP unit was used $\geq 4$ h per night on $\geq 70 \%$ of the nights, average mask leaks were $<0.4 \mathrm{~L} / \mathrm{min}$, residual AHI downloaded from the autoCPAP device was $<10 / \mathrm{h}$.

Patients were reviewed by a sleep apnea nurse educator before and after auto-CPAP titration. Auto-CPAP downloads were reviewed by a sleep medicine physician. If the auto-CPAP titration was deemed acceptable and patient was willing to proceed with long-term CPAP therapy, he or she was provided with a fixed-pressure CPAP unit at no charge (as per Saskatchewan provincial policy) at the P95 level of pressure derived from the auto-CPAP titration on the same day as their post-titration appointment.

\section{Data analysis}

Subject demographics and referral data were extracted from the Sleep Disorders Centre electronic database and loaded into $\mathrm{R}$ version 2.15.2 (11). Independent $t$ tests and $\chi^{2}$ tests were used to test disease severity, OSA diagnosis rates and program transitions, and multiple linear and logistic regressions were used to control for demographic and disease variables. Cumulative incidence curves were created for studying wait times using Kaplan-Meier analysis, while Cox proportional hazards regression was used to control for other factors.

\section{RESULTS}

The number of patients referred to and processed by the HM and SL programs are listed in Table 1, in addition to demographic and disease severity summaries. There had been a significant decrease in the number of patients referred to SL, from 1257 per year to 764 per year between 2009 and 2012, while the number of patients referred to HM has held steady for the first four years of the program.

The number of SL procedures increased slightly since 2009, from slightly $>900$ to 1250 in 2012 . No clinically significant change in patient demographics (including age, sex and body mass index [BMI]) was detected between 2009 and 2012. Patients were predominantly middle-age men with high BMI (90\% obese and 19\% morbidly obese), but there was no clinically significant difference between the SL and HM BMIs. There was no change in disease severity over time in SL or HM. The proportion of patients with OSA was $77 \%$ in $\mathrm{HM}$ and $82 \%$ in SL $(P<0.0001)$, which is a small but statistically significant difference, with no significant change over time.

Overall failures rates (technical or equipment failures) for level III testing were low $(3.8 \%)$, while auto-CPAP failures, requiring subsequent referral to the sleep laboratory, were higher (20.4\%). The proportion of patients transitioning from $\mathrm{HM}$ to SL has remained relatively constant between 2009 and 2012, sitting slightly $<20 \%$, with no significant change over time $(\mathrm{P}=0.3458)$ (Table 2$)$. The transition to in-lab testing from a negative level III test has dropped over time, from $35 \%$ in 2009 to $21 \%$ in $2012(\mathrm{P}=0.027)$.

\section{Wait times}

For patients in the HM pathway, their wait time can be partitioned into two sections: the time from referral to level III testing; and from level III to auto-CPAP. For the SL program, the wait is from referral to appointment with the laboratory.

At the end of 2012, the median wait time for HM testing was 42 days, a significant improvement for the previous years $(\mathrm{P}<0.0001)$. For time from level III testing to auto-CPAP titration, the median wait was 47 days in 2012, another significant improvement over the previous years $(\mathrm{P}<0.0001)$. For in-lab testing, the median wait time was 92 days, a significant improvement over the previous years $(\mathrm{P}<0.0001)$. Table 3 presents a summary of the wait times, and Figures 1, 2 and 3 present the cumulative incidence curves for each of the three wait times. The table and figures demonstrate both the consistent improvement in the wait times of the program overall, and the shorter waits for HM compared with SL.

There is an issue with the SL wait times that needs to be addressed to fully understand how patients are progressing through the system. Table 4 presents the number of patients processed according to referral 
TABLE 2

Transition rates from home monitoring (HM) to sleep $\operatorname{lab}^{*}(\mathrm{SL})$

\begin{tabular}{lrrrr}
\hline & $\mathbf{2 0 0 9}$ & \multicolumn{1}{c}{$\mathbf{2 0 1 0}$} & \multicolumn{1}{c}{$\mathbf{2 0 1 1}$} & \multicolumn{1}{c}{$\mathbf{2 0 1 2}$} \\
\hline HM then SL & $67(19)$ & $95(21)$ & $79(18)$ & $87(16)$ \\
HM only & $280(81)$ & $367(79)$ & $355(82)$ & $449(84)$ \\
$\begin{array}{l}\text { Negative level III } \\
\text { HM then SL }\end{array}$ & $52(35)$ & $48(34)$ & $52(27)$ & $33(21)$ \\
HM only & $97(65)$ & $92(66)$ & $139(73)$ & $122(79)$ \\
\hline
\end{tabular}

Data presented as $n(\%)$. */n-laboratory polysomnography

TABLE 3

Patient wait times for home monitoring and sleep lab* (SL), stratified according to referral year

\begin{tabular}{lcccc}
\hline & \multicolumn{4}{c}{ Referral year } \\
\cline { 2 - 5 } & $\mathbf{2 0 0 9}$ & $\mathbf{2 0 1 0}$ & $\mathbf{2 0 1 1}$ & $\mathbf{2 0 1 2}$ \\
\hline Time to level III testing & & & \\
Patients, $\mathrm{n}^{\dagger}$ & 476 & 428 & 475 & 353 \\
25\%, days & 71 & 34 & 45 & 22 \\
Time, days, median & 138 & 70 & 61 & 42 \\
75\%, days & 171 & 98 & 75 & 62 \\
Level III to Auto & & & & \\
Patients, $\mathrm{n}$ & 354 & 281 & 305 & 274 \\
25\%, days & 44 & 55 & 68 & 28 \\
Time, days, median & 81.5 & 88 & 98 & 47 \\
$75 \%$, days & 114 & 123 & 148 & 85 \\
Time to SL & & & & \\
Patients, $\mathrm{n}$ & 994 & 1018 & 795 & 647 \\
25\%, days & 31 & 60 & 40 & 27 \\
Time, days, median & 152 & 232 & 132 & 92 \\
$75 \%$, days & 1028 & 846 & 545 & 301 \\
\hline
\end{tabular}

*In-laboratory polysomnography; †Only includes patients who were referred and underwent a procedure. The difference between these numbers and the referrals shown in Table 1 represent patients who were referred to the program but did not undergo a procedure. Auto Automatic continuous positive pressure airway therapy

year for each of the four referral years. As the table indicates, the number of patients being processed in each of these windows has not changed, with the exception of 2012. In the previous three years, the number of patients processed in each window was relatively constant, with 2009 and 2010 having longer wait times largely because patients in these years were capable of waiting $\geq 2$ years. A significant improvement occurred in 2012, however, in which a large group of patients were processed in the one-to three-month window. This improvement suggests that wait times are finally coming down.

The current Canadian Thoracic Society guidelines suggest that patients with severe disease should be investigated within one month, but only $46 \%$ of patients met that deadline in 2012 (63\% were studied within ywo months and $80 \%$ within six months). Table 5 presents the percentage of severe patients investigated within one, two and six months over time, and demonstrates that, although the program is improving, the program still fails to meet the Canadian Thoracic Society wait times for the majority of its patients.

\section{DISCUSSION}

The present study was the largest retrospective analysis of the use of a home-management pathway for OSA in Canada. Our study confirms the feasibility of unattended level III monitoring in a selected group of patients with moderate to high pretest probability of OSA. The referral patterns for sleep apnea assessment and management have changed significantly since the inception of our HM program in 2009, and the proportion of patients referred and managed by the HM pathway has increased every year since program implementation and now constitutes $>40 \%$ of all OSA referrals. This has resulted in significant

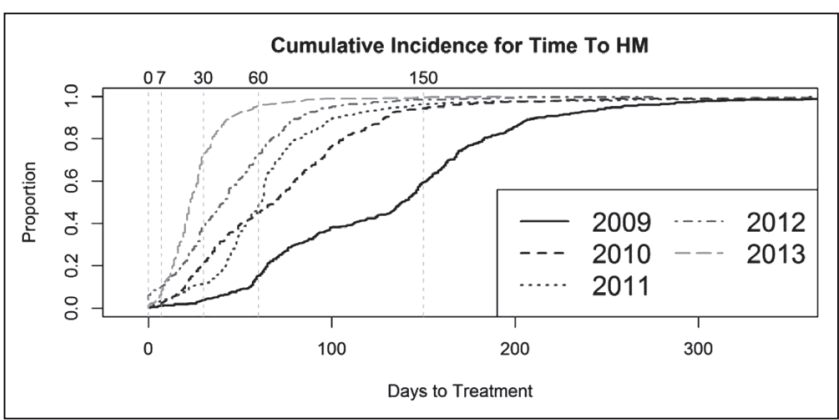

Figure 1) Wait times for level III testing. HM Home monitoring

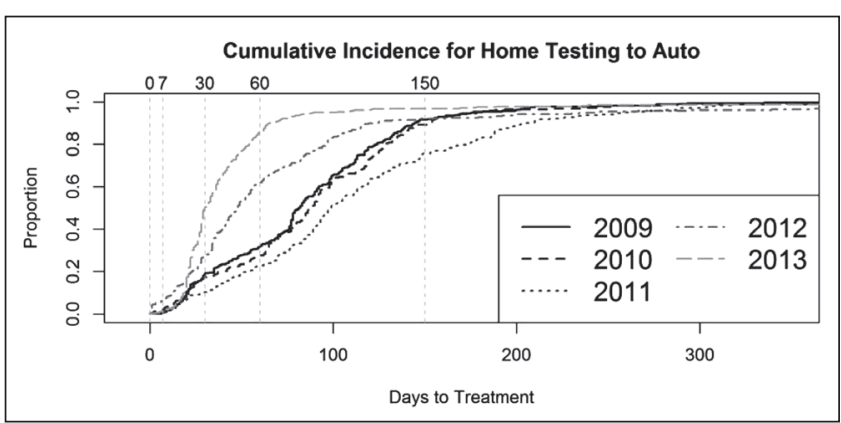

Figure 2) Wait times from level III testing to automatic continuous positive pressure airway (Auto) treatment

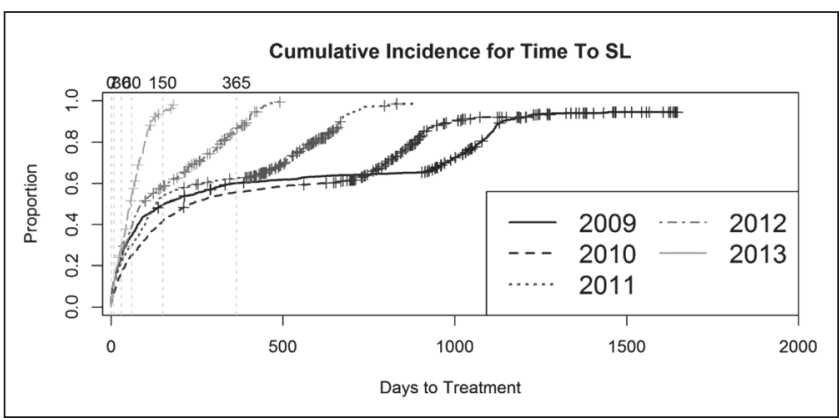

Figure 3) Wait times for in-laboratory polysomnography (sleep lab [SL])

improvement in wait time for diagnosis and CPAP therapy, shortening the time for in-lab PSG and improving access overall.

There has been an increase in the number of procedures per year since 2009, while the OSA diagnosis rate has held steady (approximately $80 \%$ ), a promising finding that suggests that the system is not being overburdened by inappropriate referrals. The lack of change in disease severity in both SL and HM patients confirms that there was not a tendency to study progressively less-severe patients over time as the number of procedures increased; therefore, there remains a burden of disease in the population to be met.

There was a consistent decrease in number of referrals from 2009 to 2012. This is a worrying trend because it raises the question of whether wait times are truly dropping due to the HM pathway or because of a decreased patient population. Our belief is that the SL referrals dropped in 2011 and 2012 because some patients were referred for private home-based testing. The present study does, however, demonstrate that the wait times for sleep apnea testing have decreased considerably over the past five years. Although the present study was not designed to explain the improvement in the wait times, we can postulate four inter-related causes. First, the private OSA management system has drawn patients from the public system, particularly in the 2009 to 2012 era, when the wait times were at their longest. Now that the system can guarantee shorter waits, patients may be less willing to pay for private management. Second, better management of the wait list itself within the program, causing a reduction in missed 
TABLE 4

Time waiting for sleep lab* (SL) according to referral year

\begin{tabular}{lcccc}
\hline Waiting for & \multicolumn{4}{c}{ Referral year } \\
\cline { 2 - 5 } SL, days & $\mathbf{2 0 0 9}$ & $\mathbf{2 0 1 0}$ & $\mathbf{2 0 1 1}$ & $\mathbf{2 0 1 2}$ \\
\hline $0-7$ & $94(9.9)$ & $73(7.3)$ & $77(9.9)$ & $75(11.8)$ \\
$>7-28$ & $144(15.2)$ & $119(11.9)$ & $110(14.2)$ & $128(20.1)$ \\
$>28-90$ & $218(23)$ & $195(19.5)$ & $163(21)$ & $186(29.2)$ \\
$>90-365$ & $195(20.5)$ & $312(31.1)$ & $235(30.3)$ & $212(33.2)$ \\
$>365-720$ & $46(4.8)$ & $87(8.7)$ & $181(23.3)$ & $37(5.8)$ \\
$>720$ & $252(26.6)$ & $216(21.6)$ & $10(1.3)$ & $0(0)$ \\
\hline
\end{tabular}

Data presented as $n(\%)$. *In-laboratory polysomnography

appointments and fewer patients remaining on this list for multiple years. Third, the HM pathway provides an alternative, reducing the workload in the SL and allowing the SL to focus on particularly sick patients. Finally, an increase in capacity in the SL system. The compliance with national guidelines for wait times for patients with suspected severe OSA has improved, but $54 \%$ of patients with severe OSA are still waiting $>30$ days for diagnosis and therapy; therefore, the gains witnessed in 2012 need to continue to ensure timely management of the most severe patients.

The HM to SL transition numbers raise some concern for the SL wait times moving forward. Patients with negative level III testing should be managed in-lab due to the low specificity of level III testing compared with in-lab PSG, particularly at low AHI values (12). Moving forward, more effort should be made to ensure that negative level III tests are followed up with in-lab PSG in an effort to reduce the false-negative rate of the program overall.

The data regarding wait times for OSA management in Canada are scarce. One study from Ontario demonstrated significant delays in accessing CPAP therapy, even in the province with the highest per capita rates of in-lab PSGs (3). An article from the Public Health Agency of Canada (13) reported significant variability in access to diagnosis across provinces and suggests that the majority of OSA patients have not been diagnosed. Current guidelines recommend that most patients should be diagnosed and treated within six months, while individuals with pre-existing cardiovascular conditions or at risk for occupational accidents within four weeks; however, compliance with these guidelines in Canada has not yet been evaluated.

The diagnosis and management of OSA has undergone significant changes recently. Data from five randomized controlled trials

\section{REFERENCES}

1. Evans J, Skomro R, Driver H, et al. Sleep laboratory test referral in Canada: Sleep Apnea Rapid Response survey. Can Respir J 2014;21:e4-e10.

2. Young T, Peppard PE, Gottlieb DJ. Epidemiology of obstructive sleep apnea: A population health perspective. Am J Respir Crit Care Med 2002;165:1217-39.

3. Rotenberg B, George C, Sullivan K, Wong E. Wait times for sleep apnea care in Ontario: A multidisciplinary assessment. Can Respir J 2010;17;170-4.

4. Skomro RP, Gjevre J, Reid J, et al. Outcomes of home-based diagnosis and treatment of obstructive sleep apnea. Chest 2010;138:257-63.

5. Chai-Coetzer CL, Antic NA, McEvoy RD. Ambulatory models of care for obstructive sleep apnoea: Diagnosis and management. Respirology 2013;18:605-15.

6. Mulgrew AT, Fox N, Ayas NT, et al. Diagnosis and initial management of obstructive sleep apnea without polysomnography: A randomized validation study. Ann Intern Med 2007;146:157-66.

7. Berry RB, Hill G, Thompson I, et al. Portable monitoring and autotitration versus polysomnography for the diagnosis and treatment of sleep apnea. Sleep 2008;31:1423-32.

8. Rosen CL, Auckley D, Benca R et al. A multisite randomized trial of portable sleep studies and positive airway pressure autotitration versus laboratory-based polysomnography for the diagnosis and treatment of obstructive sleep apnea; the HomePAP study. Sleep 2012;35:757-67.
TABLE 5

Sleep lab* patients with severe disease meeting wait time objectives

\begin{tabular}{lllll}
\hline & \multicolumn{4}{c}{ Year } \\
\cline { 2 - 5 } Wait time & $\mathbf{2 0 0 9}$ & $\mathbf{2 0 1 0}$ & $\mathbf{2 0 1 1}$ & $\mathbf{2 0 1 2}$ \\
\hline Within 30 days & 36.7 & 29.3 & 37.5 & 45.9 \\
Within 60 days & 46.7 & 39.5 & 46.1 & 62.7 \\
Within 180 days & 66.3 & 62.4 & 75.1 & 79.9 \\
\hline
\end{tabular}

Data presented as \%. *In-laboratory polysomnography

demonstrate that, in selected patients, outcomes of home-based diagnosis and management are not inferior to those of in-lab PSG (14), while a recent systematic review confirms these findings in OSA patients (12). As the diagnostic accuracy of HM testing approaches that of SL, the utility of HM increases dramatically.

Results of the present study should be interpreted with caution. Our HM program has been carefully designed so that entry criteria for patients into the HM pathway were standardized from the very beginning. All level III tests were scored by both PSG technician and read by a sleep medicine consultant, and all patients were seen by a sleep apnea nurse educator. These results, therefore, may not be generalizable to other jurisdictions and practice patterns. The same level III device was used in all patients. Recent evidence indicates that there are $>14$ such devices marketed in Canada (15). The results from our study, therefore, may not be generalizable to other devices. The present study did not assess the economic impact of the HM pathway. There remains considerable debate as to whether home-based management pathways are more cost effective than in-lab PSGs (16). Low failure rates for our level III test and auto-CPAP titrations are encouraging, but detailed cost effectiveness of this approach remain lacking in Canada.

ACKNOWLEDGEMENTS: RS, JR, EP, MF, JG and DC gathered the data; SAS analyzed the data; SAS and RS wrote the manuscript; MF, EP, JR, JG and DC edited and revised the manuscript. The authors acknowledge the Lung Association of Saskatchewan, the Department of Medicine in the College of Medicine at the University of Saskatchewan and the Saskatchewan Health Region for their continued support of this research.

DISCLOSURES: The authors have no financial disclosures or conflicts of interest to declare.

9. Antic NA, Buchan C, Esterman A, et al. A randomized controlled trial of nurse-led care for symptomatic moderate-severe obstructive sleep apnea. Am J Respir Crit Care Med 2009;179:101-8.

10. Berry RB, Budhiraja R, Gottlieb DJ, et al. Rules for scoring respiratory events in sleep: Update of the 2007 AASM Manual for the Scoring of Sleep and Associated Events. Deliberations of the Sleep Apnea Definitions Task Force of the American Academy of Sleep Medicine. J Clin Sleep Med 2012;8:597-619.

11. R Core Team (2012). R: A language and environment for statistical computing. R Foundation for Statistical Computing, Vienna, Austria. ISBN 3-900051-07-0.

12. El Shayeb M, Topfer LA, Stafinski T, Pawluk L, Menon D. Diagnostic accuracy of level 3 portable sleep tests versus level 1 polysomnography for sleep-disordered breathing: A systematic review and meta-analysis. CMAJ 2014;186:E25-51.

13. What is the impact of sleep apnea on Canadians? Fast facts from the 2009 Canadian Community Health Survey - sleep apnea rapid response. Ottawa: Public Health Agency of Canada; 2009.

14. Corral-Peñafiel J, Pepin JL, Barbe F. Ambulatory monitoring in the diagnosis and management of obstructive sleep apnoea syndrome. Eur Respir Rev 2013;22:312-24.

15. Pietzsch JB, Garner A, Cipriano LE, et al. An integrated healtheconomic analysis of diagnostic and therapeutic strategies in the treatment of moderate-to-severe obstructive sleep apnea. Sleep 2011;34:695-709.

16. Andreu AL, Chiner E, Sancho-Chust JN, et al. Effect of an ambulatory diagnostic and treatment programme in patients with sleep apnoea. Eur Respir J 2012;39:305-12. 


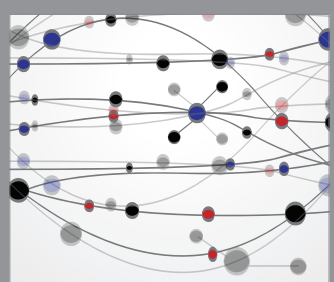

The Scientific World Journal
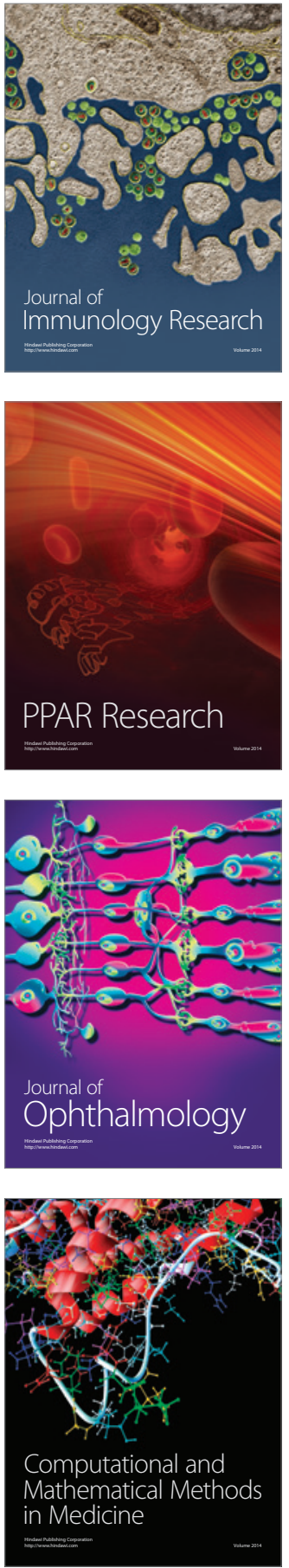

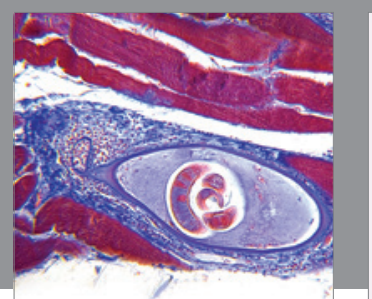

Gastroenterology Research and Practice

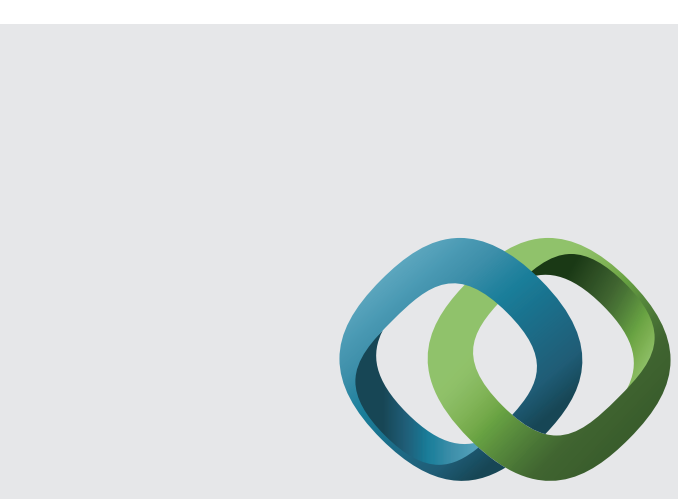

\section{Hindawi}

Submit your manuscripts at

http://www.hindawi.com
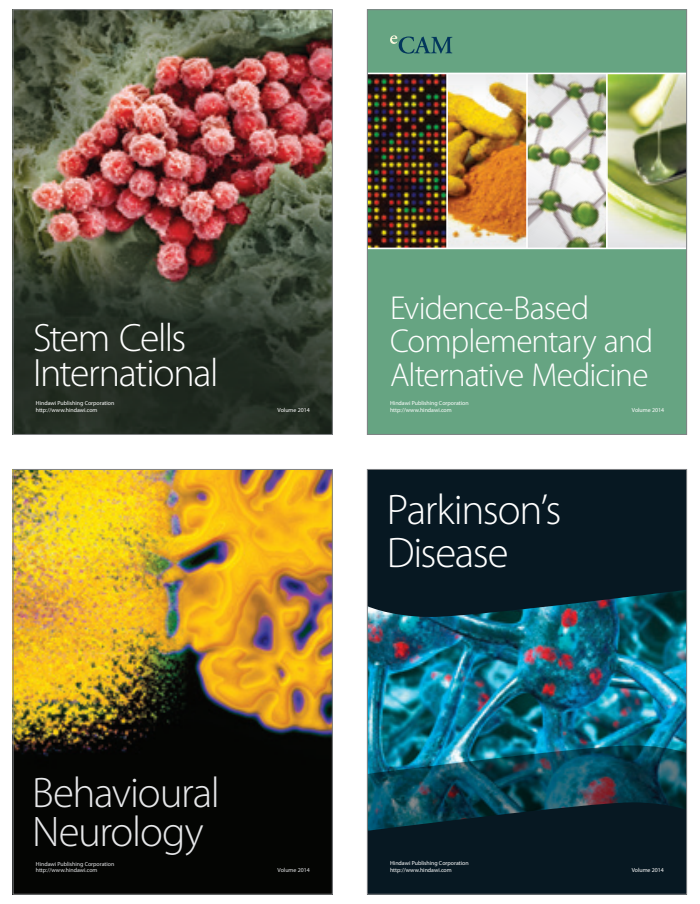
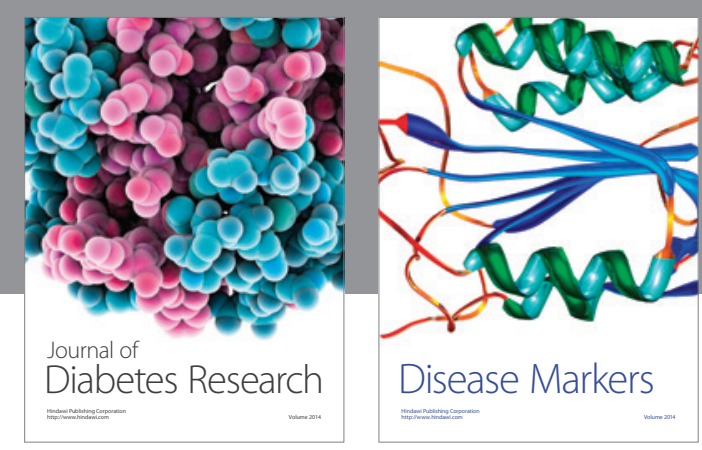

Disease Markers
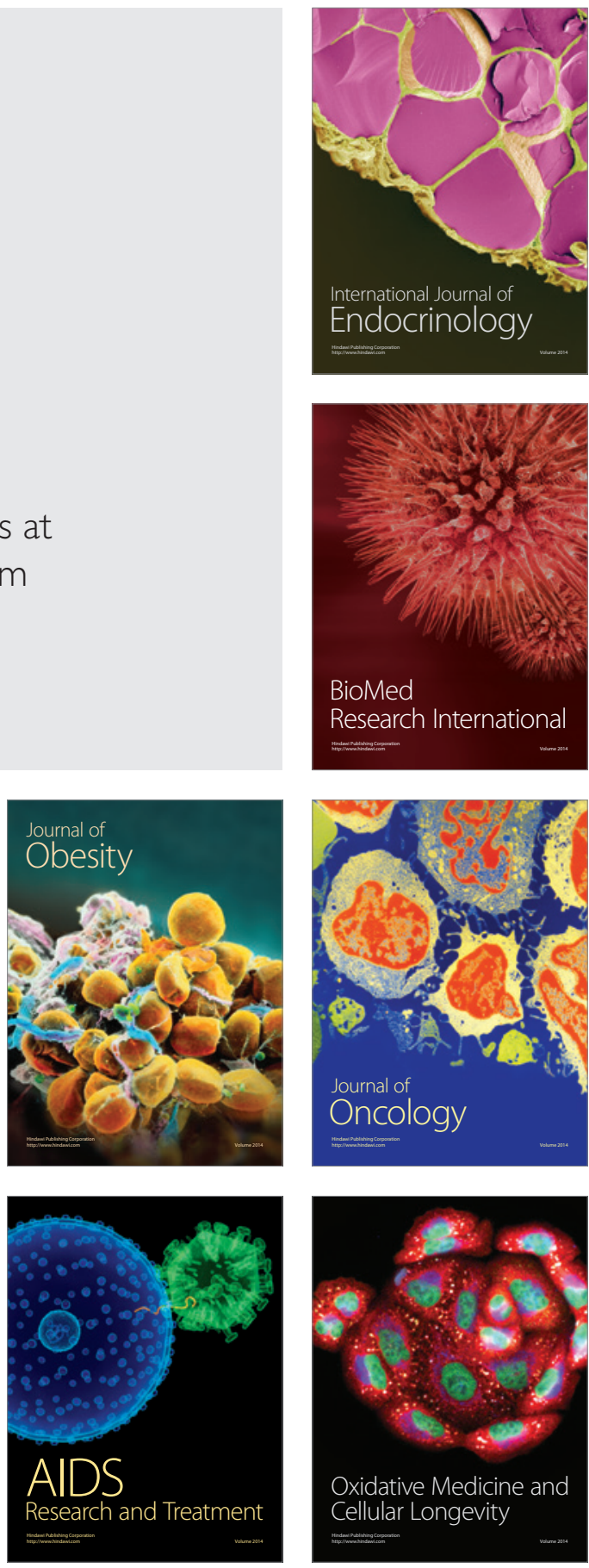